\title{
FUNGICIDE TIMING FOR THE CONTROL OF SEPTORIA TRITICI BLOTCH OF WHEAT
}

\author{
M.V. MARRONI, S.L.H. VILJANEN-ROLLINSON, R.C. BUTLER \\ and Y. DENG
}

Crop \& Food Research, Private Bag 4704, Christchurch, New Zealand

Corresponding author: viljanens@crop.cri.nz

\begin{abstract}
A field trial during the 2005-06 growing season used different fungicides and timing of fungicide applications to manipulate the development of septoria tritici blotch on artificially-inoculated wheat (cv. Consort). Disease severity was assessed once or twice a week and the area under the disease progress curve (AUDPC) calculated. The fungicide azoxystrobin applied at the pre-stem extension stage of crop growth had the lowest AUDPC and provided the best level of protection against the disease on the top three leaves. Good control of the disease was also obtained from pre-stem extension and stem-extension (growth stage GS32) applications of a mixture of azoxystrobin and epoxiconazole. Epoxiconazole applied at the pre-stem extension stage and azoxystrobin and epoxiconazole mixture applied at growth stages 37 and 39 did not provide adequate control of the disease. This work is part of a project aiming to provide information for development of disease models and forecast systems to assist growers with disease control decisions.

Keywords: Septoria tritici, Mycosphaerella graminicola, wheat, fungicide, azoxystrobin, epoxiconazole, area-under-the-disease-progresscurve, AUDPC.
\end{abstract}

\section{INTRODUCTION}

Septoria tritici blotch (STB), caused by Septoria tritici Roberge in Desmaz. (teleomorph Mycosphaerella graminicola (Fückel) J. Schrot.), can seriously affect foliage of autumn-sown wheat (Triticum aestivum) crops in New Zealand and other wheat-growing regions of the world. Severe yield losses can occur in crops when the top two or three leaves (flag, second and third leaf of wheat plants) become infected. These leaves are important for grain filling and final yield (Shaw \& Royle 1989). New Zealand farmers aim to protect these leaves from STB, typically using fungicides applied on three occasions, at full emergence of leaf three, the flag leaf and at flowering. Weather-based STB prediction models can assist growers to make decisions about the need and timing for fungicide sprays based on weather conditions (Thomas et al. 1989; Shtienberg et al. 1990; Moreau et al. 1999; Audsley et al. 2005). Such models have the potential to be used by New Zealand growers, but they need to be validated under local conditions.

In a previous study, the mean latent period of $\mathrm{cv}$. Consort in the field varied between 21 and 27 days (Armour et al. 2004). This paper reports a field trial that aimed to define disease progress up the plant after application of different fungicide treatments at different growth stages of the crop. This work is part of a project aiming to provide information for development of disease models and forecast systems to assist growers with disease control decisions. 


\section{MATERIALS AND METHODS}

A field trial was established at Lincoln, Canterbury, New Zealand, during the 20052006 growing season, using two different fungicides (Opus ${ }^{\circledR}$ : epoxiconazole $125 \mathrm{~g}$ ai/ha and Amistar ${ }^{\Theta}$ : azoxystrobin $250 \mathrm{~g}$ ai/ha), alone or in combination, and four different timings to manipulate the spread of STB on wheat cv. Consort (Table 1). There were four replicates of fungicide treatments and eight replicates of the Nil treatment, laid out in an array of eight rows of four plots, in a resolvable row and column design. There were two Nil treatment plots within each replicate (two rows of four plots), and a complete replicate in each column of plots.

Before treatments were applied, plants were inoculated with $S$. tritici. Three $S$. tritici isolates (2SC2, 2SC3 and 2SC4) previously tested for their pathogenicity to wheat were selected from the Crop \& Food Research culture collection and cultured in liquid media as described by Eyal et al. (1987). Isolates were mixed prior to field inoculation, spore concentration was adjusted to $1 \times 10^{7}$ spores $/ \mathrm{ml}$ and a drop of Tween 20 was added to the inoculum mixture. The trial was inoculated on 8 September 2005 with the spore suspension, using a motorised knapsack sprayer calibrated to deliver 200 litres/ha.

Disease assessments were carried out 12 times, initially 1 month apart and thereafter weekly or twice weekly. At each date, 10 plants were randomly selected per plot and scored for the percentage of leaf area infected with $S$. tritici. At the initial assessment on 7 October 2005, the flag leaf and leaves F-1, F-2 and F-3 had not emerged, but all had emerged by the second assessment on 10 November 2005. The final assessment was on 30 December 2005, by which time almost all leaves on the Nil treatment plants were dead.

TABLE 1: List of treatments used in the field experiment.

\begin{tabular}{|c|c|c|}
\hline Treatment & Description & Date applied \\
\hline Nil & Nil fungicide (double replicates) & \\
\hline Pre-epoxiconazole & $\begin{array}{l}\text { Pre stem extension - epoxiconazole applied at } \\
\text { GS30-31 (pseudo stem erection to first node } \\
\text { detectable) }\end{array}$ & $16 / 09 / 2005$ \\
\hline Pre-azoxystrobin & $\begin{array}{l}\text { Pre stem extension - azoxystrobin applied at } \\
\text { GS30-31 }\end{array}$ & $16 / 09 / 2005$ \\
\hline Pre-Mix & $\begin{array}{l}\text { Pre stem extension - mixture of azoxystrobin } \\
\text { and epoxiconazole applied at GS30-31 }\end{array}$ & $16 / 09 / 2005$ \\
\hline GS32-Mix & $\begin{array}{l}\text { Stem extension - mixture of azoxystrobin and } \\
\text { epoxiconazole applied at GS32 (second node } \\
\text { detectable) }\end{array}$ & $20 / 10 / 2005$ \\
\hline GS37-Mix & $\begin{array}{l}\text { Stem extension - mixture of azoxystrobin and } \\
\text { epoxiconazole applied at GS37 (flag leaf } \\
\text { just visible) }\end{array}$ & $9 / 11 / 2005$ \\
\hline GS39-Mix & $\begin{array}{l}\text { Stem extension - mixture of azoxystrobin and } \\
\text { epoxiconazole applied at GS39 (flag leaf ligule } \\
\text { just visible) }\end{array}$ & $18 / 11 / 2005$ \\
\hline
\end{tabular}

The mean disease severity on each leaf for each treatment at each date (prior to the substitutions made below for the area under the disease progress curve (AUDPC) calculation) is presented. Prior to the calculation of AUDPC, dead leaves were given a score equal to the mean score for that plot and leaf number at the previous date. Once all the leaves of a given number in a plot were dead, scores for this leaf were omitted from subsequent dates from the calculation of AUDPC. After these substitutions, the mean 
scores per leaf per plot per date were calculated, and were used to calculate AUDPC using the formula:

$$
\mathrm{AUDPC}=\sum_{d=0}^{n} \frac{1}{2}\left(y_{i+1}+y_{i}\right)\left(x_{i+1}-x_{i}\right)
$$

where $Y_{l}=\mathrm{STB}$ severity at the $i$ th observation, $X_{I}=$ time (d) at the $i$ th observation and $n=$ total number of observations (observations until all dead). Values of AUDPC were analysed with analysis of variance, with the Greenhouse-Geisser adjustment ("repeated measures anova") as implemented in GenStat, since the leaves were measured on the same plots.

\section{RESULTS}

The mean disease severities on each leaf for each treatment at each date are presented in Figure 1. The highest disease severities were in the Nil, GS37-Mix and GS39Mix plots. The lowest disease severities were in the pre-azoxystrobin, Pre-Mix and GS32-Mix plots. This is also illustrated in the mean AUDPC for each treatment for each date (Table 2). There was a significant interaction between the treatments and leaf number $(\mathrm{P}<0.001)$, with the pattern in AUDPC across the leaves varying substantially between the treatments. The differences were mainly for flag to leaf F-4, with differences between treatments on leaves F-5 to F-7 not significant ( $P>0.50)$. Almost all leaves F-5 to F-7 had died by the second assessment.

For flag to F-4, AUDPC was less than the Nil at all leaves for treatments Preazoxystrobin, Pre-Mix and GS32-Mix. The Pre-azoxystrobin treatment gave the lowest AUDPC on each of these leaves, followed by Pre-Mix. On the flag and F-4, AUDPC for the Pre-epoxiconazole treatment was very similar to that for the Nil, but for leaves F-1 to F-3, AUDPC was less than the Nil, although more than for the best three treatments. For the remaining two treatments (GS37-Mix and GS39-Mix) the change in AUDPC from flag to F-4 followed a similar pattern to the Nil, although AUDPC was less $(\mathrm{P}<0.05)$ except for F-2 and F-3.

TABLE 2: Mean area under the disease progress curve (AUDPC) for different leaves of wheat for fungicide treatments applied at three different stages of crop growth (GS30-31, GS32, GS37 and GS39).

\begin{tabular}{|c|c|c|c|c|c|c|c|}
\hline Leaf & Nil & $\begin{array}{l}\text { Pre-epoxi- } \\
\text { conazole }\end{array}$ & $\begin{array}{l}\text { Pre-azoxy- } \\
\text { strobin }\end{array}$ & Pre-Mix & $\begin{array}{l}\text { GS32- } \\
\text { Mix }\end{array}$ & $\begin{array}{l}\text { GS37- } \\
\text { Mix }\end{array}$ & $\begin{array}{l}\text { GS39- } \\
\text { Mix }\end{array}$ \\
\hline Flag & 551 & 623 & 43 & 73 & 202 & 137 & 265 \\
\hline F-1 & 1801 & 1004 & 99 & 169 & 319 & 814 & 1417 \\
\hline $\mathrm{F}-2$ & 2114 & 1238 & 216 & 343 & 468 & 2108 & 2094 \\
\hline $\mathrm{F}-3$ & 2128 & 1277 & 255 & 436 & 538 & 2449 & 2241 \\
\hline $\mathrm{F}-4$ & 608 & 645 & 127 & 224 & 279 & 177 & 288 \\
\hline F-5 & 306 & 193 & 199 & 64 & 287 & 300 & 223 \\
\hline F-6 & 383 & 159 & 306 & 102 & 274 & 402 & 230 \\
\hline F-7 & 355 & 147 & 307 & 179 & 261 & 410 & 254 \\
\hline \multicolumn{8}{|c|}{ LSD $\mathrm{P}<0.05$ to compare: } \\
\hline \multicolumn{4}{|c|}{ Between leaves $(\mathrm{df} \approx 79)$} & \multicolumn{4}{|c|}{ Between treatments $(\mathrm{df} \approx 95)$} \\
\hline Nil & & \multicolumn{2}{|l|}{207.3} & \multicolumn{2}{|l|}{ Nil } & \multicolumn{2}{|l|}{252.3} \\
\hline \multicolumn{2}{|c|}{ Other treatments } & \multicolumn{2}{|l|}{293.2} & \multicolumn{2}{|c|}{ Other treatments } & \multicolumn{2}{|l|}{291.6} \\
\hline
\end{tabular}




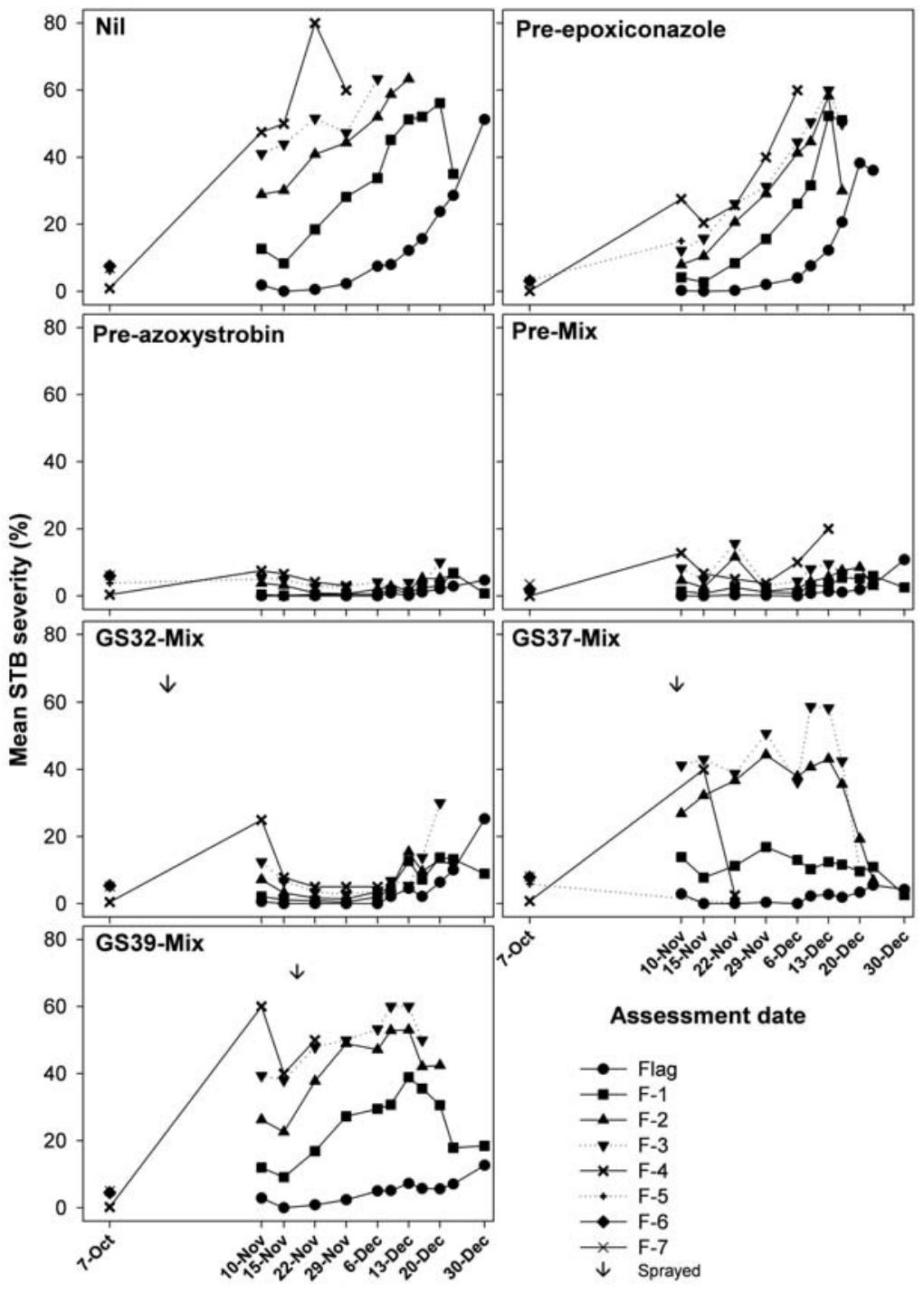

Assessment date

FIGURE 1: Mean septoria tritici blotch severity (percent leaf area infected) for different leaves of wheat for fungicide treatments applied at crop growth stages $($ pre-stem extension $=$ GS30-31; stem extension $=$ GS32, GS37 and GS39) during the 2005-2006 growing season. Arrows indicate dates when each treatment was sprayed with fungicide. Applications on 16 September for treatments Pre-epoxiconazole, Preazoxystrobin and Pre-Mix are not shown. 


\section{DISCUSSION}

Current measures for STB control rely predominantly on the use of fungicides, even though resistant cultivars are available. Fungicides used in this study are from different chemical groups but they have both protectant and eradicant activity. The efficiency of azoxystrobin in controlling $S$. tritici is mostly attributed to its systemic action and inhibition of spore germination, but it also has some eradicant activity (Godwin et al. 1999). Epoxiconazole is a sterol biosynthesis inhibitor with a prolonged persistence and eradicant activity (Schöfl \& Zinkernagel 1997). It is recommended that fungicides be targeted to protect green leaf area of the top three leaves, as these are the most important contributors to yield (Shaw \& Royle 1989). The greatest damage from STB is caused when severe disease occurs on the top two leaves, but severe disease on leaf three can also be damaging (Thomas et al. 1989).

Early applications of a protectant fungicide can provide good protection for several weeks although they will not cure established disease (Godwin et al. 1999). These results indicated that the pre-azoxystrobin treatment, with azoxystrobin applied at an early stage of crop development when disease levels were low, provided very good eradication of the early infection and good protection of leaves, including the top three leaves. The pre-epoxiconazole treatment, with the fungicide epoxiconazole applied at an early stage of crop development, may have suppressed initial inoculum levels but not to the same degree as the pre-azoxystrobin treatment. This agrees with work by Godwin et al. (1994) who found that azoxystrobin strongly inhibits the early stages of the $S$. tritici infection, whereas epoxiconazole does not. The Pre-Mix treatment, a mixture of azoxystrobin and epoxiconazole, provided a similar degree of protection to the pre-azoxystrobin treatment. Pre-Mix combined the eradicant and protectant effect of both fungicides and provided good control of the disease, although STB severity on some leaves increased slightly towards the end of the growing season. According to Godwin et al. (1999), mixtures of azoxystrobin with a strong eradicant product such as epoxiconazole can result in improved control of STB. However, results from the present work were similar to other experiments carried out in New Zealand, where superior control of STB has been achieved using azoxystrobin alone, compared with other protectant and eradicant fungicides (Cromey et al. 2000; I.C. Harvey \& B. McCloy, unpubl. data).

A mixture of azoxystrobin and epoxiconazole delayed until growth stage GS32 (GS32-Mix) showed higher levels of disease severity on leaf F-4 than in pre-azoxystrobin and Pre-Mix treatments. Severity was low during November, but increased particularly on the flag leaf and leaf F-3 from December compared with pre-azoxystrobin and Pre-Mix.

GS37-Mix, a mixture of azoxystrobin and epoxiconazole applied at growth stage GS37, showed high levels of disease particularly on leaves F-2 and F-3, whereas leaf F-1 had moderate disease severity and the flag leaf showed low disease severity, similar to pre-azoxystrobin and Pre-Mix. Leaves that emerged earlier (F-5 to F-7) were already dead at the beginning of November and leaf F-4 was dead at the end of November. It appeared that the eradicant activity of epoxiconazole combined with the protection of azoxystrobin provided good enough STB control to maintain the flag leaf and leaf F-1 with low and moderate disease severity respectively. However, the treatment was too late to control disease on leaves F-2 to F-4 or lower leaves that were already dead by the time the treatment was applied.

GS39-Mix, a mixture of azoxystrobin and epoxiconazole applied at growth stage GS39, showed a trend similar to GS37-Mix, although disease severity was higher for each leaf. However, flag leaves remained with low to moderate disease severity, indicating that although the treatment was applied when the flag leaf was fully unfolded, it provided eradicant and protective activity to maintain the leaf within those levels of disease.

Early applications of fungicides appeared best for control of STB in wheat. In UK, yield losses due to absence of disease control can occur from GS32 (Cook et al. 1999). Current recommendations in UK are to spray at GS32 and again at GS39, but in certain instances additional applications may be required especially during early disease outbreaks (Anon. 
2006). Although not yet encountered in New Zealand, resistance to the azoxystrobin and other QoI fungicides is now common in Europe (Lucas 2003). Hence the current recommendations are to use a maximum of two strobilurin fungicide sprays in any one season and always in a mixture with a triazole fungicide (Anon. 2006).

\section{ACKNOWLEDGEMENTS}

Funding for this research was provided by the New Zealand Foundation for Research, Science and Technology. We thank Cathy Munro for sowing and managing the trial.

\section{REFERENCES}

Anon. 2006. The wheat disease management guide. www.hgca.com (accessed 29 May 2006).

Armour T, Viljanen-Rollinson SLH, Chng S, Butler RC, Jamieson PD, Zyskowski RF 2004. Examining the latent period of septoria tritici blotch in a field trial of winter wheat. New Zealand Plant Protection 57: 116-120.

Audsley E, Milne A, Paveley N 2005. A foliar disease model for use in wheat disease management decision support systems. Annals of Applied Biology 147: 161-172.

Cook RJ, Hims MJ, Vaughan TB 1999. Effects of fungicide spray timing on winter wheat disease control. Plant Pathology 48: 33-50.

Cromey MG, Braithwaite M, Alexander BJR, Ganev S, Cookson TR 2000. Control of speckled leaf blotch of wheat with fungicides. New Zealand Plant Protection 53: 103-108.

Eyal Z, Scharen AL, Prescott JM, Ginkel MV 1987. The septoria diseases of wheat: concepts and methods of disease management. CIMMYT, Mexico City, Mexico. $52 \mathrm{pp}$.

Godwin JR, Young JE, Hart CA 1994. ICIA5504: effects on development of cereal pathogens. Brighton Crop Protection Conference - Pests and Diseases. Pp. 259-264.

Godwin JR, Bartlett DW, Heaney SP 1999. Azoxystrobin: implications of biochemical mode of action. Pharmacokinetics and resistance management for spray programmes against septoria diseases of wheat. In: Lucas JA, Bowyer P, Anderson HM ed. Septoria on cereals: a study of pathosystems. CABI Publishing, Wallingford, UK. Pp. 299-315.

Lucas JA 2003. Resistance to QoI fungicides: Implications for cereal disease management in Europe. Pesticide Outlook 14(6): 268-270.

Moreau JM, Maraite H, Knight JD 1999. Integration of knowledge on wheat phenology and Septoria tritici epidemiology into a disease risk simulation model validated in Belgium. Information technology for crop protection, Harpenden, UK. No. 55. Pp. 1-6.

Schöfl UA, Zinkernagel VA 1997. A test method based on microscopic assessments to determine curative and protectant fungicide properties against Septoria tritici. Plant Pathology 46: 545-556.

Shaw MW, Royle DJ 1989. Airborne inoculum as a major source of Septoria tritici (Mycosphaerella graminicola) infections in winter wheat crops in the UK. Plant Pathology 38: 35-43.

Shtienberg D, Dinoor A, Marani A 1990. Wheat disease control advisory, a decision support system for management of foliar diseases of wheat in Israel. Canadian Journal of Plant Pathology 12(2): 195-203.

Thomas MR, Cook RJ, King JE 1989. Factors affecting development of Septoria tritici in winter wheat and its effect on yield. Plant Pathology 38(2): 246-257. 